\title{
Reticulação de Plastissóis de PVC Utilizando Resina Epóxi Polifuncional: Síntese e Caracterização
}

\author{
Ívi Martins de Carvalho, Lucia Helena Innocentini Mei \\ Departamento de Engenharia de Materiais e Bioprocessos, Faculdade de Engenharia Química, UNICAMP \\ Antonio Rodolfo Junior \\ Braskem S/A
}

\begin{abstract}
Resumo: Plastissois reticulados de PVC foram obtidos por meio de espalmagem, na presença de uma resina epóxi polifuncional tipo tetraglicidilmetilenodianilina (TGMDA). A presença de um amino acelerador, baseado numa poliaminoamida comercial, mostrou-se imprescindível para a ocorrência de reticulação das cadeias do PVC. Resultados de grau de reticulação mostraram que só houve formação de gel nas amostras onde o amino acelerador foi utilizado concomitantemente com a resina epóxi, evidenciando uma sinergia entre ambos. Apesar dos resultados de módulo de Young sugerirem a formação de uma rede tridimensional entre as moléculas do PVC e a resina epóxi, a comprovação de uma reação química de reticulação entre o PVC e a resina epóxi não foi possível, devido ao grande numero de moléculas presentes na formulação final. Entretanto, a evidência de que a reticulação de fato ocorreu poderá vir de estudos mais detalhados e o uso de outras técnicas de caracterização complementares, já iniciados.
\end{abstract}

Palavras-chave: PVC, poli(cloreto de vinila), plastissol, resina epóxi, polímeros hiperramificados, reticulação.

\section{Crosslinking of PVC Plastisols Using a Polyfunctional Epoxy Resin: Synthesis and Characterization}

Abstract: PVC plastisols, crosslinked in the presence of a polyfunctional epoxy resin, were obtained via spread coating. It was possible to infer that the presence of an amine type accelerator, at least in the conditions used in this study, proved to be essential for crosslinking. The results of reticulation degree showed that gel formation only happened in samples where the amine type accelerator has been used concomitantly with the epoxy resin. The results of Young's modulus seem to confirm the hypothesis of formation of a three dimensional network between the molecules of PVC and epoxy resin, but it was not possible to confirm a chemical reaction between these two polymers because of the large number of molecules present in the formulation. Evidence that crosslinking actually occurred may come from more detailed studies and the use of complementary characterization techniques, which are underway.

Keywords: PVC, poly(vinyl chloride), plastisol, epoxy, hyperbranched polymers, crosslinking.

\section{Introdução}

O PVC, ou poli(cloreto de vinila), é o segundo termoplástico mais consumido em todo o mundo, com uma demanda mundial de resina superior a 36 milhões de toneladas no ano 2011, sendo a capacidade mundial de produção de resinas de PVC estimada em cerca de 50 milhões t/ano ${ }^{[1]}$. Desta demanda total, aproximadamente $70 \%$ foram consumidos na China, América do Norte e nos países da Europa Ocidental. Na América do Sul foram consumidos cerca de 5\%, sendo o Brasil responsável pelo consumo de cerca de um milhão de toneladas anuais, ou cerca de pouco mais de $2 \%$ da demanda mundial de resinas de PVC. Estes dados mostram o potencial de crescimento da demanda de resinas de PVC no mercado interno, uma vez que o consumo per capita, da ordem de $5 \mathrm{~kg} / \mathrm{hab}$./ano, ainda é baixo comparado a outros países.

O PVC pode ser considerado um dos plásticos mais versáteis, podendo apresentar características de extrema flexibilidade ou rigidez, mediante a incorporação de aditivos, para atender um amplo espectro de propriedades, em função da aplicação final ${ }^{[2]}$. Dentre os vários tipos de compostos de PVC, plastissois e organossois estão entre os mais versáteis, pois oferecem várias possibilidades de se obter novos produtos. A tecnologia utilizada para se obter esses materiais torna possível o uso de uma grande variedade de processos de moldagem e recobrimento (espalmagem ou spread coating), os quais permitem variar seu grau de flexibilidade, até a obtenção de materiais duros e rígidos (rigissois) ${ }^{[3]}$.

Dentre as varias possibilidades de se trabalhar o PVC, a obtenção de uma estrutura hiperramificada, bem como dendrímeros, constituem-se de uma importante área de estudo da Ciência dos Polímeros, e deverão encontrar utilidade em aplicações onde essa especificidade estrutural tem grande potencial. Embora já se tenha alcançado muito progresso no entendimento estrutural e dos métodos de síntese destes polímeros, a compreensão de seus derivados funcionais e utilidades dos mesmos estão ainda, relativamente, nos primórdios ${ }^{[4]}$.

Trabalhos como de Karmalm et al. ${ }^{[5]}$ relatam que a formação de uma estrutura reticulada contribui

Autor para correspondência: Lucia Helena Innocentini Mei, Departamento de Engenharia de Materiais e Bioprocessos - DEMBio, Faculdade de Engenharia Química, Universidade Estadual de Campinas - Unicamp, Av. Albert Einstein, 500, CEP 13083-852, Campinas, SP, Brasil, e-mail: lumei@feq.unicamp.br 
para a melhora da estabilidade térmica do PVC, o que ampliaria em muito sua faixa de aplicações. Em uma das alternativas, esta estabilidade seria conferida pela reação de abertura do anel epoxídico e consequente estabilização do átomo de cloro lábil, evitando a geração de $\mathrm{HCl}$ originado durante a degradação da cadeia.

López et al. ${ }^{[6]}$, por sua vez, avaliaram misturas de resina epóxi com plastissois de PVC, em diferentes proporções. Materiais diferentes, com propriedades desde a rigidez de uma resina termoendurecível, até a flexibilidade de um plastisol convencional, foram desta maneira obtidos. Esses autores observaram que dependendo da proporção entre a resina epóxi e o plastisol, o material resultante se assemelhava ao de materiais termoplásticos.

O objetivo desse trabalho teve como foco a preparação de plastissois de PVC modificados pela incorporação de uma resina epóxi polifuncional, e o estudo de seu processo de reticulação durante o processamento em presença de um amino acelerador. Neste artigo são apresentados os resultados da avaliação dos efeitos do teor de resina epóxi e do amino acelerador no processo de reticulação do plastisol de PVC.

\section{Experimental}

\section{Materiais}

A formulação do composto de PVC, tomada como referência e resumida na Tabela 1 , baseou-se nas práticas comuns utilizadas nos transformadores de espalmados de PVC. Resina de PVC com valor K $78 \pm 1$, fornecida pela Braskem S/A (Norvic P78LM), foi utilizada como matriz polimérica principal. A estabilização térmica da formulação foi efetuada através da incorporação de um sal de Ba/Zn comercial (Baerostab UBZ 790V), fornecido pela Baerlocher do Brasil S/A.

Como plastificantes foram utilizados tanto o di-octilftalato ou DOP (Scandiflex do Brasil S/A

Tabela 1. Formulação básica do plastisol utilizado nos experimentos.

\begin{tabular}{lc}
\hline \multicolumn{1}{c}{ Componente } & Teor (pcr) \\
\hline Norvic P78LM & 100 \\
Baerostab UBZ 790 V & 0,5 \\
DOP & 60 \\
OSE & 2 \\
\hline
\end{tabular}

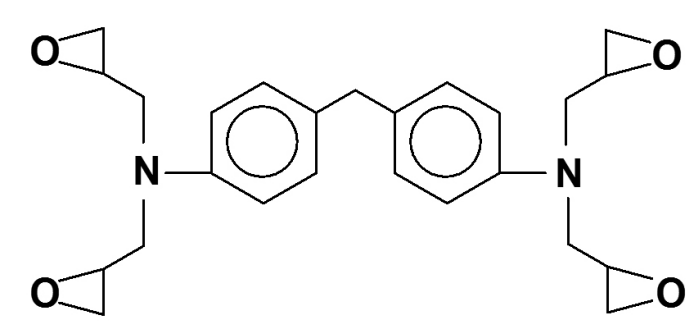

(a)
Indústrias Químicas), quanto o óleo de soja epoxidado ou OSE (Celuflex, Resypar Indústria e Comércio Ltda.), plastificante primário e secundário, respectivamente. A presença do OSE apresenta efeito sinergístico com os sais de $\mathrm{Ba}$ e $\mathrm{Zn}$ do estabilizante térmico, atuando portanto como um co-estabilizante ${ }^{[2]}$.

$\mathrm{O}$ agente de reticulação estudado foi uma resina epóxi, tetraglicidilmetilenodianilina (TGMDA), fornecida pela Momentive Química do Brasil Ltda., com o nome comercial Epikote 496. Foram estudados ainda os efeitos da incorporação de um agente acelerador baseado em poliaminoamida $60 \%$ (teor tipicamente utilizado na indústria ${ }^{[7]}$ ), gentilmente cedido pela Brascola Ltda., e aqui denominado amino acelerador. A Figura 1 apresenta as estruturas químicas da resina epóxi e desse amino acelerador. A Figura 2, por sua vez, apresenta o mecanismo normalmente aceito para o processo de reticulação de resinas epóxi, a partir da reação com aminas.

\section{Planejamento experimental}

De forma a otimizar a avaliação dos efeitos do teor de resina epóxi e amino acelerador no processo de reticulação do plastisol de PVC, um planejamento fatorial completo do tipo $3^{2}$ foi realizado. $\mathrm{O}$ fator resina epóxi foi avaliado nos teores de 0,5 e 10 pcr, enquanto que o fator amino acelerador foi avaliado nos teores de 0,1 e 10 pcr. Desta maneira, os nove experimentos resultantes, apresentados na Tabela 2, permitiram a avaliação dos efeitos dos fatores estudados, bem como eventuais interações, com um nível de significância estatística adequado. Para auxiliar na análise estatística dos resultados, particularmente na construção das tabelas de análise de variância (ANOVA) e gráficos de efeitos e interações, empregou-se o software Minitab 16.

\section{Preparação dos plastissois e processamento}

Os plastissois foram preparados misturando-se a resina de PVC (pó) e demais aditivos da formulação (todos líquidos) em um misturador tipo Cowles, a $1000 \mathrm{rpm}$, com aplicação posterior de vácuo, para a retirada de bolhas. Nos casos aplicáveis, a resina epóxi e o amino acelerador foram incorporados junto com os demais aditivos, nos teores indicados na Tabela 2 .

Folhas de aproximadamente $1 \mathrm{~mm}$ de espessura foram produzidas em uma espalmadeira de laboratório Mathis, na temperatura de $180{ }^{\circ} \mathrm{C}$, com tempo de residência no forno igual a 1,5 min. Esta condição foi a que se mostrou

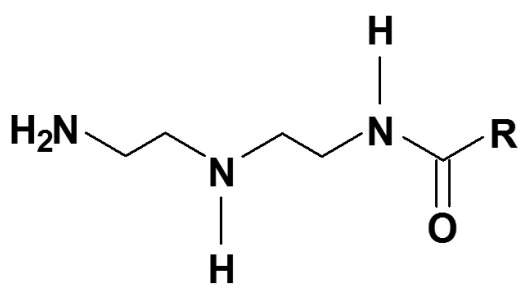

(b)

Figura 1. Estruturas químicas da resina epóxi tipo tetraglicidilmetilenodianilina (a) e do amino acelerador poliaminoamida (b) 
mais otimizada, após ensaios prévios com diferentes condições de tempo e temperatura.

\section{Determinação do grau de reticulação}

O grau de reticulação pós-processamento, para cada uma das formulações estudadas, foi determinado através do teor de gel, via extração com solvente em extrator Sohxlet. Amostras das folhas espalmadas foram cortadas em pequenos pedaços e submetidas à extração com tetrahidrofurano ou THF (considerado um solvente forte para o PVC), em refluxo por 24 horas. O material resultante foi então seco em estufa a $70{ }^{\circ} \mathrm{C}$, até atingir<smiles>[R]OCC1CO1</smiles><smiles>[R]NCC(O)CO[R]</smiles><smiles>[R]OCC1CO1</smiles><smiles>[R]OCC(O)CN([R])CC([2H])(O)CO[R]</smiles>

Figura 2. Mecanismo genérico de reticulação de resinas epóxi, através da reação com aminas, segundo Müller e Poth ${ }^{[7]}$.

Tabela 2. Planejamento experimental utilizado para o estudo das interações entre as duas variáveis estudadas (teor de resina epóxi e teor de amino acelerador), em três níveis.

\begin{tabular}{ccc}
\hline Formulação & $\begin{array}{c}\text { Teor de resina } \\
\text { epóxi (pcr) }\end{array}$ & $\begin{array}{c}\text { Teor de amino } \\
\text { acelerador (pcr) }\end{array}$ \\
\hline F1 & 0 & 0 \\
F2 & 0 & 1 \\
F3 & 0 & 10 \\
F4 & 5 & 0 \\
F5 & 5 & 1 \\
F6 & 5 & 10 \\
F7 & 10 & 0 \\
F8 & 10 & 1 \\
F9 & 10 & 10 \\
\hline
\end{tabular}

peso constante, e o teor de gel foi obtido através da Equação 1:

$$
\text { Teor de gel }(\%)=\frac{\mathrm{W}_{\mathrm{s}}}{\mathrm{W}_{\mathrm{i}}} \times 100
$$

Onde $\mathrm{W}_{\mathrm{s}}$ é a massa da amostra não solúvel (g), e $\mathrm{W}_{\mathrm{i}}$ é a massa inicial da amostra (g). Os ensaios foram realizados em duplicata.

\section{Espectroscopia no infravermelho por transformada de Fourier (FT-IR)}

Espectros no infravermelho foram obtidos em um equipamento Nicolet 6700 , com resolução de $4 \mathrm{~cm}^{-1}$, equipado com um acessório de reflexão total atenuada (ATR) tipo Smart Omni-Sampler, diretamente na superfície das folhas produzidas por espalmagem. Um total de 32 varreduras por amostra foi tomada para garantir a resolução adequada dos espectros.

\section{Propriedades mecânicas na tração}

Propriedades de tração (módulo de Young, tensão de ruptura e alongamento na ruptura) foram determinadas em cinco corpos de prova ASTM D638-10 tipo V, para cada formulação, em uma máquina universal de ensaios MTS modelo Alliance 5/RT, na velocidade de $50 \mathrm{~mm} / \mathrm{min}$. Os ensaios foram realizados na temperatura de $(23 \pm 2)^{\circ} \mathrm{C}$.

\section{Resultados e Discussões}

\section{Grau de reticulação}

A Tabela 3 apresenta os resultados obtidos na caracterização das amostras preparadas. Observa-se que, para a ocorrência de reticulação nas condições de processamento empregadas neste estudo, a presença do amino acelerador mostrou-se imprescindível. Observa-se ainda que as amostras contendo somente resina epóxi, ao contrário da expectativa inicial, não apresentaram nenhum indício de reticulação, ao menos nas condições de processamento empregadas.

O mecanismo de estabilização da molécula do PVC, através de óleos epoxidados, é bem conhecido ${ }^{[2,8,9]}$. Acredita-se que o grupo oxirana, presente nos óleos epoxidados, participe dos processos de transferência de $\mathrm{HCl}$ para o estabilizante térmico principal, e da troca de cloretos lábeis da estrutura do polímero por grupos do estabilizante. Contrário à expectativa inicial, onde era esperado que a simples presença da resina epóxi polifuncional em meio às cadeias de PVC seria suficiente para promover sua reticulação, os resultados mostram que este processo ocorreu somente na presença do amino acelerador.

É também conhecido ${ }^{[8,10]}$ que aminas, quando presentes nas formulações de PVC, atuam como fortes promotores da reação de desidrocloração, tal como demonstrado na Figura 3. As amostras preparadas apresentaram forte alteração da coloração do filme espalmado, com a presença e o aumento do teor de amino acelerador. Entretanto, os resultados da Tabela 3, em função da ausência de gel no final do processo de extração 

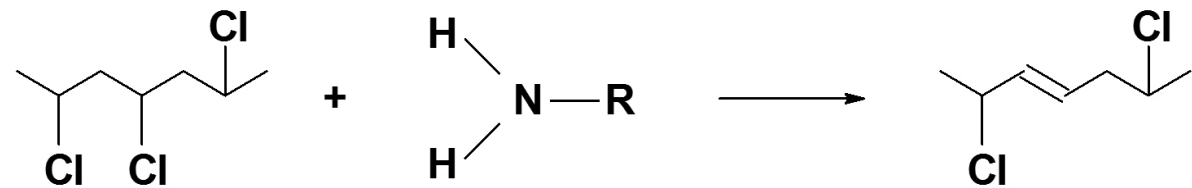

$+\mathrm{RNH}_{3} \mathrm{Cl}$

Figura 3. Desidrocloração de resinas de PVC na presença de aminas, segundo Yousaf, Qureshi e Ahmad ${ }^{[9]}$.

Tabela 3. Grau de reticulação, inferido a partir dos resultados de teor de gel, e propriedades de tração das amostras estudadas.

\begin{tabular}{ccccccc}
\hline Formulação & $\begin{array}{c}\text { Teor de resina } \\
\text { epóxi (pcr) }\end{array}$ & $\begin{array}{c}\text { Teor de amino } \\
\text { acelerador (pcr) }\end{array}$ & Teor de gel (\%) & $\begin{array}{c}\text { Tensão de } \\
\text { ruptura (MPa) }\end{array}$ & $\begin{array}{c}\text { Alongamento na } \\
\text { ruptura (\%) }\end{array}$ & $\begin{array}{c}\text { Módulo de Young } \\
\text { (MPa) }\end{array}$ \\
\hline F1 & 0 & 0 & $0,0 \pm 0,0$ & $15,9 \pm 1,4$ & $634 \pm 111$ & $6,6 \pm 0,5$ \\
F2 & 0 & 1 & $0,0 \pm 0,0$ & $15,0 \pm 1,4$ & $335 \pm 27$ & $8,2 \pm 2,2$ \\
F3 & 0 & 10 & $0,0 \pm 0,0$ & $10,7 \pm 1,6$ & $267 \pm 33$ & $6,0 \pm 0,2$ \\
F4 & 5 & 0 & $0,0 \pm 0,0$ & $16,3 \pm 1,2$ & $354 \pm 27$ & $6,6 \pm 0,3$ \\
F5 & 5 & 1 & $0,0 \pm 0,0$ & $15,1 \pm 2,0$ & $358 \pm 44$ & $6,1 \pm 0,1$ \\
F6 & 5 & 10 & $58,0 \pm 0,0$ & $9,5 \pm 1,8$ & $179 \pm 40$ & $8,1 \pm 0,1$ \\
F7 & 10 & 0 & $0,0 \pm 0,0$ & $16,5 \pm 2,3$ & $663 \pm 128$ & $6,0 \pm 0,0$ \\
F8 & 10 & 1 & $0,0 \pm 0,0$ & $12,8 \pm 1,7$ & $320 \pm 50$ & $5,6 \pm 0,3$ \\
F9 & 10 & 10 & $37,9 \pm 0,1$ & $9,8 \pm 1,1$ & $172 \pm 30$ & $8,8 \pm 0,4$ \\
\hline
\end{tabular}

por Sohxlet, também mostram que a simples presença do amino acelerador não promoveu a formação de ligações cruzadas entre as cadeias do PVC, nas condições de processamento empregadas. Aparentemente, os resultados obtidos indicam que a reação de reticulação ocorreu entre as moléculas do PVC e da resina epóxi. Esta ultima, em função de sua funcionalidade igual a 4, atuou como um ponto de ligação entre diferentes cadeias do PVC, promovendo sua reticulação.

Observando-se os teores de resina epóxi e amino acelerador presentes nas duas situações em que ocorreu reticulação (formulações F6 e F9), verifica-se que estes dois componentes, se reagissem somente entre si e na totalidade empregada nas formulações, resultaria em teores de gel de aproximadamente $8,5 \%$ no caso da formulação F6, e 11,0\% no caso da formulação F9, sendo ambos os valores muito inferiores aos encontrados experimentalmente. Isso pode ser explicado se considerar-se que parte da resina de PVC sofreu reticulação concomitantemente com a resina epóxi, na presença do amino acelerador, permanecendo na fração insolúvel durante a extração com THF.

\section{Espectroscopia no infravermelho por transformada de Fourier (FT-IR)}

A Figura 4 apresenta, como referência da posição dos picos de absorção na região do infravermelho, os espectros de FT-IR da resina epóxi e do óleo de soja epoxidado, utilizados na formulação dos plastissois de PVC estudados. Observa-se no espectro da resina epóxi os principais picos característicos relativos à sua estrutura $^{[11-14]}$, com destaque para os picos referentes ao anel epóxi, localizados na região do espectro entre 800 e $830 \mathrm{~cm}^{-1}$, bem como em $1230 \mathrm{~cm}^{-1}$. Segundo a literatura ${ }^{[13]}$, o acompanhamento destes picos, em estudos dinâmicos aplicando a técnica de FT-IR no processo de reticulação de resinas epóxi na presença de aminas, mostra seu progressivo desaparecimento com a progressão da reação de reticulação, bem como o aparecimento de um pico largo entre 3300 e $3500 \mathrm{~cm}^{-1}$, correspondente ao grupo hidroxila, confirmando o mecanismo de reação apresentado anteriormente na Figura 2.

No caso do espectro na região do infravermelho do OSE, podem ser identificados diversos picos correspondentes às características estruturais deste plastificante secundário ${ }^{[15]}$, sendo notório o pico na região de $1740 \mathrm{~cm}^{-1}$, correspondente ao grupo éster, responsável pela polaridade necessária à compatibilização com a resina de PVC. Importante notar que, embora visíveis, os picos relativos ao anel epóxi entre 800 e $830 \mathrm{~cm}^{-1}$ são bastante discretos e, mais importante, não prejudicam a possibilidade de visualização dos picos correspondentes na resina epóxi e seu acompanhamento nas diferentes formulações de plastissol avaliadas neste trabalho. Em função da elevada concentração na resina epóxi, estes picos são muito mais intensos que no caso do OSE, uma vez que nesta substância a concentração de epóxi é muito menor, em função de sua estrutura ${ }^{[10]}$.

A Figura 5, por sua vez, apresenta os espectros de FT-IR de filmes espalmados selecionados, comparativamente aos espectros da resina epóxi e do amino acelerador. De maneira a simplificar a apresentação dos resultados, foram selecionadas as formulações F1 (plastisol base), F7 (10 pcr de resina epóxi) e F9 (10 pcr de resina epóxi +10 pcr de endurecedor tipo amina), pois de outra forma a quantidade de curvas sobrepostas seria excessiva, prejudicando a observação dos detalhes estruturais. Nestes espectros observa-se o fortalecimento da banda de $1500 \mathrm{~cm}^{-1}$, indicando o aumento da concentração do amino acelerador na formulação.

Segundo a literatura ${ }^{[16,17]}$, a tarefa de interpretar um espectro de infravermelho é facilitada quando esta se inicia a partir de uma fórmula estrutural previamente conhecida. Porém, quando se trata da análise qualitativa de misturas, estas podem ser identificadas desde que as frações de seus componentes estejam presentes em uma concentração que permita sua identificação com confiança. No caso de formulações de PVC, pela ampla 


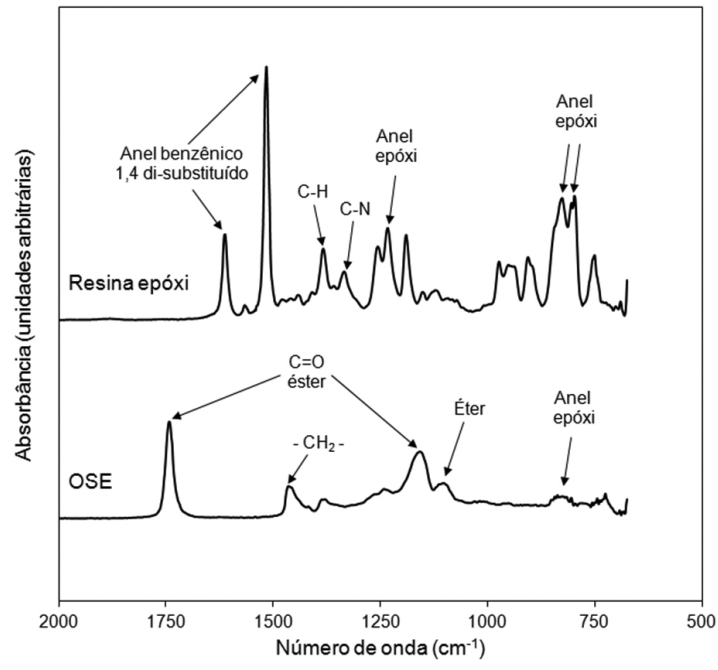

Figura 4. Detalhe dos espectros de FT-IR da resina epóxi e do óleo de soja epoxidado. diversidade de aditivos utilizados em sua composição, esta tarefa torna-se ainda mais complicada, como se pode observar na Figura 5, para a situação da formulação F1, denotada 0:0, onde nota-se a intensa sobreposição de picos.

Bandas características do grupo amida, na região de $3280 \mathrm{~cm}^{-1}$, bem como em $1650 \mathrm{~cm}^{-1}$, são facilmente identificadas no espectro do amino acelerador ${ }^{[16-19]}$. Dois picos bastante intensos, em $2850 \mathrm{~cm}^{-1}$ e $2920 \mathrm{~cm}^{-1}$, característicos do segmento alifático desta molécula, são também facilmente visualizados.

Examinando-se os espectros de FT-IR para as formulações selecionadas, apresentados na Figura 5, não é possível identificar a presença dos picos característicos da resina epóxi, pois os picos localizados na região do espectro entre 800 e $830 \mathrm{~cm}^{-1}$ não são aparentes. Além disso, o pico localizado em $1230 \mathrm{~cm}^{-1}$, se presente, encontra-se sobreposto por um pico muito intenso em $1270 \mathrm{~cm}^{-1}$, correspondente ao plastificante $\mathrm{DOP}^{[20,21]}$, presente em todas as formulações estudadas. Entretanto, um exame cuidadoso dos espectros de FT-IR das
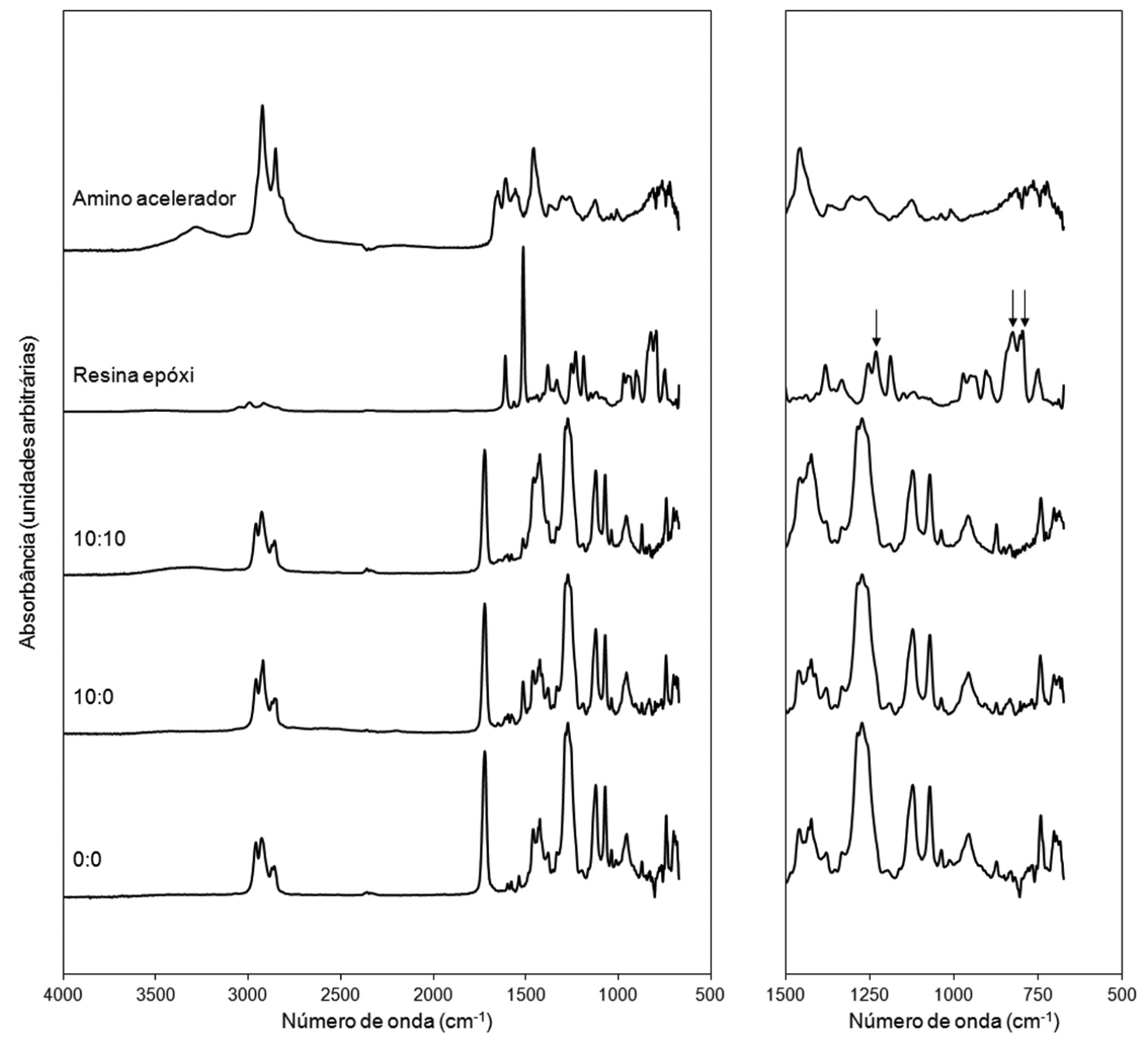

Figura 5. Espectros de FT-IR da resina epóxi, do amino acelerador, e de filmes espalmados selecionados, em função do teor de resina epóxi : amino acelerador. À direita, detalhe da região dos picos do anel epóxi, indicados pela setas. 
formulações F7 (10 pcr de resina epóxi, denotada 10:0) e F9 (10 pcr de resina epóxi +10 pcr de amino acelerador, denotada 10:10), apresenta indícios de um pico na região entre 3300 e $3500 \mathrm{~cm}^{-1}$, correspondente ao grupo hidroxila. Esse resultado sugere que, independentemente da presença do amino acelerador, as condições de processamento empregadas aparentemente induziram a abertura do anel epóxi. Entretanto, somente na situação em que 10 pcr do amino acelerador foi empregado (formulações F6 e F9), foi possível induzir a reticulação da resina de PVC através da reação com a resina epóxi tetrafuncional. Wan et al. ${ }^{[22]}$, em um estudo que avaliou os efeitos da incorporação de uma argila modificada com sal de amônio à resina de PVC, identificaram a presença de um pico discreto, na região de $1670 \mathrm{~cm}^{-1}$, correspondente à formação das insaturações decorrentes do processo de desidrocloração da resina de PVC, induzida pelo sal de amônio. No presente estudo, entretanto, não foi possível evidenciar a presença desse pico de degradação do PVC, apesar de evidências pela coloração final das amostras pós processamento. De qualquer maneira, é reconhecido que a técnica de espectroscopia no ultravioleta é a técnica mais adequada para identificar a presença de duplas ligações conjugadas ${ }^{[23,24]}$, e infelizmente neste presente estudo não foi possível avaliar as amostras através desta técnica.

Finalmente, a Figura 6 apresenta uma proposta de mecanismo de reticulação da resina de PVC na presença de resina epóxi e amino acelerador, o qual poderá, no futuro, ser confirmado por técnicas mais específicas, como por exemplo, espectroscopia de massa.

\section{Propriedades mecânicas na tração}

A Tabela 3 também sumariza os resultados de tensão de ruptura, alongamento na ruptura e módulo de Young, das diferentes formulações estudadas. No caso da tensão de ruptura, a comparação através de ANOVA mostrou que a presença do amino acelerador afeta de maneira estatisticamente significativa essa propriedade (valor $\mathrm{p}=0,000$ ), promovendo uma progressiva redução de seus valores com o aumento de seu teor incorporado ao plastisol de PVC. Já o teor de resina epóxi, por sua vez, não afeta de maneira estatisticamente significativa os valores de tensão de ruptura das amostras (valor $p=0,223$ ). $O$ efeito da interação entre os fatores estudados também não afeta, de maneira estatisticamente significativa, a tensão de ruptura das amostras (valor $\mathrm{p}=0,342$ ). A Figura $7 \mathrm{a}$ apresenta o gráfico, gerado pelo software Minitab 16, para os efeitos das variáveis estudadas no valor da tensão de ruptura das amostras.

No caso do alongamento na ruptura, por sua vez, a comparação através de ANOVA mostrou que tanto a presença do amino acelerador, quanto o teor de resina epóxi, bem como a interação entre esses dois fatores, afetam de maneira estatisticamente significativa essa propriedade (valor $\mathrm{p}=0,000$ ). Tal como a tensão de ruptura, observa-se uma progressiva redução nos valores do alongamento na ruptura, com o aumento do teor de resina epóxi e amino acelerador incorporados ao plastisol de PVC. A Figura 7b apresenta o gráfico gerado pelo software Minitab 16, para os efeitos das variáveis
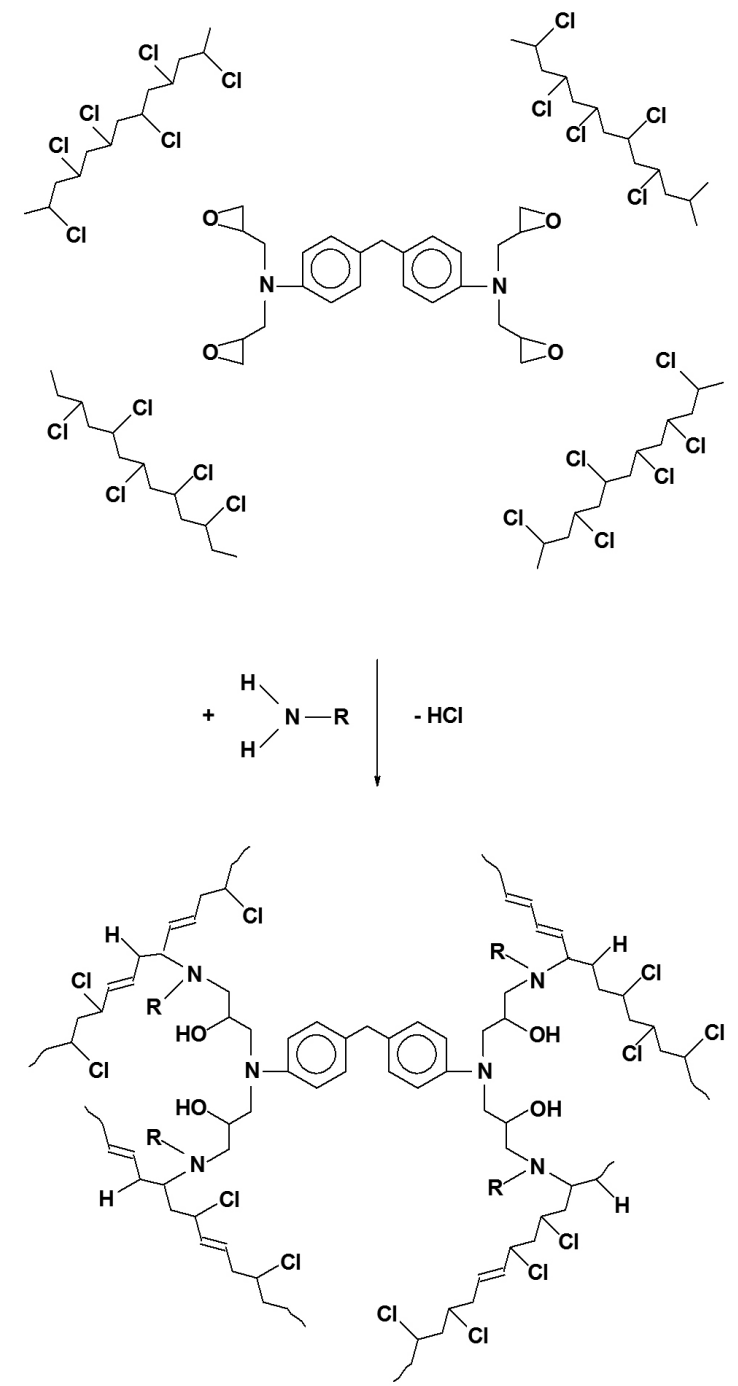

Figura 6. Possível mecanismo de reação entre a resina de PVC e a resina epóxi tetrafuncional, na presença de um amino acelerador.

estudadas no valor do alongamento na ruptura das amostras.

Os resultados de módulo de Young corroboram os resultados de teor de gel, indicando que, aparentemente, uma rede tridimensional reticulada é formada no PVC, quando na presença da resina epóxi e amino acelerador. A comparação através de ANOVA mostrou que a presença da amina afeta de maneira estatisticamente significativa essa propriedade (valor $\mathrm{p}=0,000$ ), promovendo um progressivo aumento dos valores do módulo de Young, com o aumento do teor de amino acelerador incorporado ao plastisol de PVC. Esse aumento, porém, ocorre somente na presença da resina epóxi, uma vez que o parâmetro relativo à interação entre os dois fatores estudados se mostrou também estatisticamente significativo (valor $\mathrm{p}=0,000$ ). Tal como a tensão de ruptura, o teor de resina epóxi incorporada não afeta de maneira estatisticamente significativa os valores do módulo de Young das amostras (valor $\mathrm{p}=0,877$ ). 


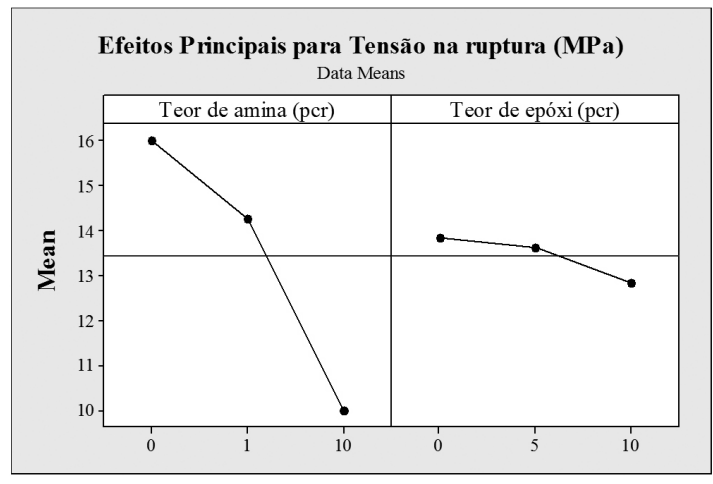

(a)

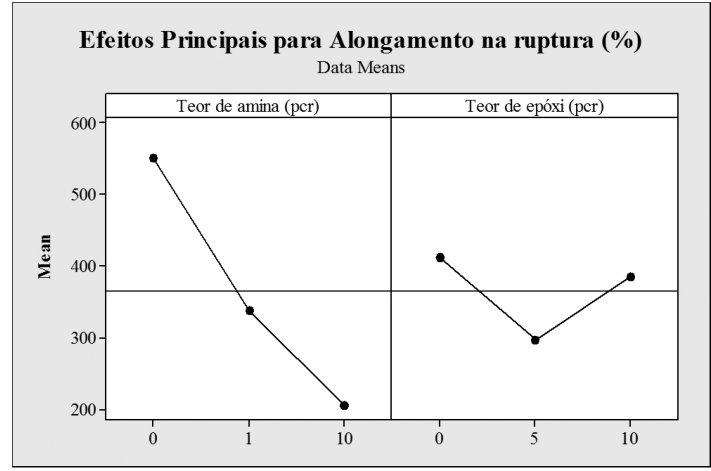

(b)

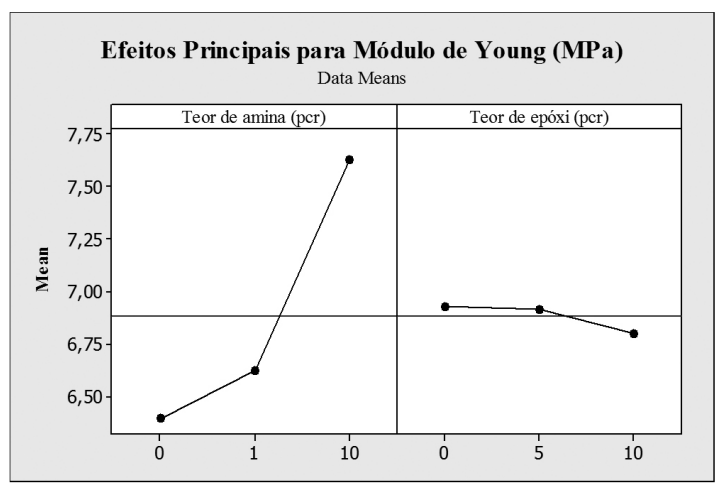

(c)

Figura 7. Gráficos, gerados pelo software Minitab 16, para os efeitos das variáveis estudadas: (a) tensão de ruptura; (b) alongamento na ruptura; e (c) módulo de Young.

A Figura 7c apresenta o gráfico, gerado pelo software Minitab 16, para os efeitos das variáveis estudadas no valor do módulo de Young das amostras.

\section{Conclusões}

Com o planejamento experimental utilizado, permite-se afirmar que a presença do amino acelerador, ao menos nas condições de processamento utilizadas, mostrou-se imprescindível para a ocorrência do processo de reticulação da resina de PVC na presença de uma resina epóxi polifuncional.
Resultados de grau de reticulação confirmam tal conclusão, uma vez que só houve formação de gel nas amostras onde o amino foi utilizado concomitantemente com a resina epóxi. A comprovação da reação química é dificultada pelo grande numero de moléculas presentes na formulação, somado ao deslocamento dos picos no espectro de FT-IR, causado pela interação entre estas. Entretanto, a análise do comportamento quanto ao módulo de Young respalda a hipótese de formação de uma rede tridimensional entre as moléculas do PVC e a resina epóxi; porém, são necessários estudos mais aprofundados para identificação do provável polímero hiperramificado formado.

Apesar de ocorrer a reticulação da resina de PVC na presença da resina epóxi e do amino acelerador, observa-se que este último é extremamente deletério para a resina de PVC devido à forte desidrocloração induzida, não sendo este capaz de melhorar as propriedades mecânicas dos plastissois de PVC; a redução significativa na resistência à tração e no alongamento na ruptura não é compensada pelo aumento no módulo de Young, ao menos nas condições estudadas até o momento. Novas rotas de reação já iniciadas, buscando-se aceleradores menos deletérios para a resina de PVC, poderão trazer bons resultados, possivelmente resultando em reforço do plastisol.

\section{Agradecimentos}

Os autores agradecem à Braskem S/A, através do programa NEO PVC (Núcleo de Estudos Orientados do PVC), pelo suporte dado a este projeto de pesquisa, e à CAPES pela concessão de bolsa para Ívi Martins de Carvalho.

\section{Referências Bibliográficas}

1. Smith, M. D. - "Global vinyls 2012: Charting the course through choppy waters", in: World Petrochemical Conference Proceedings, Chemical Market Associates, Houston (2012).

2. Rodolfo Junior, A.; Nunes, L. R. \& Ormanji, W. - “Tecnologia do PVC”, ProEditores, São Paulo (2006).

3. Wickson, E. J. - "Handbook of polyvinyl chloride formulating”, John Wiley, Nova York (1993).

4. Kim, Y. H. - J. Polym. Sci. Part A, Polym. Chem., 36, p.1685 (1998). http://dx.doi.org/10.1002/(SICI)10990518(199808)36:11<1685::AID-POLA1>3.3.CO;2-4

5. Karmalm, P.; Hjertberg, T.; Jansson, A.; Dahl, R. \& Ankner, K. - Polym. Degrad. Stab., 94, p.1986, (2009). http:// dx.doi.org/10.1016/j.polymdegradstab.2009.07.029

6. López, J.; Gisbert, S.; Ferrándiz, S.; Vilaplana, J. \& Jiménez, A. - J. Appl. Polym. Sci., 67, p.1769 (1998). http://dx.doi.org/10.1002/(SICI)10974628(19980307)67:10<1769::AID-APP10>3.0.CO;2-S

7. Müller, B. \& Poth, U. - "Coatings formulation: An international textbook”, Vincentz, Hannover (2006).

8. Titow, W. V. - "Stabilizers: General aspects”, in: Titow, W. V. (ed.), PVC technology, 4. eds., Elsevier, Londre Applied Science Publisher (1984). http://dx.doi.org/10.1007/97894-009-5614-8_9 
9. Yousaf, S. D.; Qureshi, A. \& Ahmad, Z. - Iran. Polym. J., 5, p.213 (1996).

10. Rodolfo Junior,A. \& Mei,L.H. I. -Polímeros, 17, p.263 (2007). http://dx.doi.org/10.1590/S0104-14282007000300018

11. Kaelble, D. H. \& Dynes, P. J. - "Preventive nondestructive evaluation (PNDE) of graphite-epoxy composites", in: Buckley, J. D. (ed.), Proceedings of the 2nd and 3rd annual conference on composites and advanced materials, American Ceramic Society, Columbus (1980).

12. Sewell, T. A. - "Quality assurance of graphitelepoxy by high-performance liquid chromatography", in: Browning, C. E. (ed.), Composite materials: Quality assurance and processing, American Society for Testing and Materials, Baltimore (1983). http://dx.doi.org/10.1520/STP28535S

13. Yang, J. - "Modifications of epoxy resins with functional hyperbranched poly(arylene esther)s", Tese de Doutorado, Virginia Polytechnic Institute and State University, Estados Unidos da América (1998).

14. Jaramillo, I.; Morales, C.; Betancur, A.; Cruz, J. \& Gañan, P. - Dyna, 71, p.67 (2004).

15. Adhvaryu, A. \& Erhan, S. Z. - Ind. Crop. Prod., 15, p.247 (2002). http://dx.doi.org/10.1016/S0926-6690(01)00120-0

16. Coates, J. - "Interpretation of infrared spectra, a practical approach”, in: Meyers, R. A. (ed.), Encyclopedia of analytical chemistry, John Wiley \& Sons, Chichestes (2000).

17. Günzler, H. \& Gremlich, H. U. - "IR spectroscopy: An introduction”, Wiley-VCH, Weinheim (2002).
18. Liu, Y.; Xu, W.; Xiong, Y.; Zhang, F. \& Xu, W. - Chin. J. Polym. Sci., 27, p. 343 (2009). http://dx.doi.org/10.1142/ S0256767909003984

19. Nikolic, G.; Zlatkovic, S.; Cakic, M.; Cakic, S.; Lacnjevac, C. \& Rajic, Z. - Sensors, 10, p.684 (2010). PMid:22315562 PMCid:3270863. http://dx.doi.org/10.3390/s100100684

20. Bourdeaux, D.; Sautou-Miranda, V.; Bagel-Boithias, S.; Boyer, A. \& Chopineau, J. - J. Pharmaceut. Biomed., 35, p.57 (2004). PMid:15030880. http://dx.doi.org/10.1016/j. jpba.2003.12.018

21. Ekelund, M.; Azhdar, B. \& Gedde, U. W. - Polym. Degrad. Stab., 95, p.1789 (2010). http://dx.doi.org/10.1016/j. polymdegradstab.2010.05.007

22. Wan, C.;Zhang,Y.\&Zhang Y.-Polym. Test., 23, p.299(2004). http://dx.doi.org/10.1016/j.polymertesting.2003.08.001

23. Witenhafer, D. E. - "Resins structure and properties", in: Nass, L. I. \& Heiberger, C. A. (ed.), Encyclopedia of PVC - Volume 1: Resin manufacture and properties, 2. ed., Marcel Dekker, Nova York (1986).

24. Jennings, T. C. \& Starnes Junior, W. H. - "PVC stabilizers and lubricants", in: PVC handbook, Wilkes, C. E.; Summers, J. W. \& Daniels, C. A. (ed.), Hanser Gardner Publishers, Cincinnati (2005).

Enviado: 07/03/12

Reenviado: 20/06/12

Aceito: $13 / 07 / 12$ 